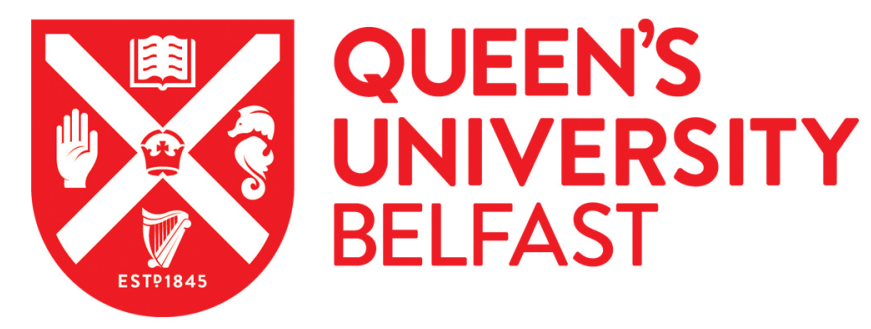

\title{
Prognosis of isolated mild to moderate fetal cerebral ventriculomegaly a systematic review
}

\author{
Devaseelan, P., Cardwell, C., Bell, B., \& Ong, S. (2010). Prognosis of isolated mild to moderate fetal cerebral \\ ventriculomegaly a systematic review. Journal of Perinatal Medicine, 38(4), 401-409. \\ https://doi.org/10.1515/JPM.2010.048
}

Published in:

Journal of Perinatal Medicine

Queen's University Belfast - Research Portal:

Link to publication record in Queen's University Belfast Research Portal

\footnotetext{
General rights

Copyright for the publications made accessible via the Queen's University Belfast Research Portal is retained by the author(s) and / or other copyright owners and it is a condition of accessing these publications that users recognise and abide by the legal requirements associated with these rights.

Take down policy

The Research Portal is Queen's institutional repository that provides access to Queen's research output. Every effort has been made to ensure that content in the Research Portal does not infringe any person's rights, or applicable UK laws. If you discover content in the Research Portal that you believe breaches copyright or violates any law, please contact openaccess@qub.ac.uk.
} 


\section{Prognosis of isolated mild to moderate fetal cerebral ventriculomegaly: a systematic review}

\author{
Priscilla Devaseelan $^{1, *}$, Chris Cardwell ${ }^{2}$, Barbara Bell ${ }^{3}$ \\ and Stephen Ong ${ }^{1}$ \\ ${ }^{1}$ Department of Obstetrics and Gynaecology, Royal Jubilee \\ Matemity Service, Belfast, UK \\ ${ }^{2}$ Department of Epidemiology and Public Health, Queen's \\ University, Belfast, UK \\ ${ }^{3}$ Department of Paediatrics, Craigavon Area Hospital, \\ Portadown, UK
}

\begin{abstract}
Aims: To ascertain risk of aneuploidy, infection and neurological abnormality for the fetus diagnosed with isolated mild $(10.1-12.0 \mathrm{~mm})$ to moderate $(12.1-15.0 \mathrm{~mm})$ cerebral ventriculomegaly and to compare the neurological outcome between symmetrical vs. asymmetrical and stable vs. progressive ventriculomegaly.

Methods: A systematic review was conducted. Literature was identified by searching two bibliographical databases between 1980 and 2009 without language restrictions. The data extracted were inspected for heterogeneity. Overall rates and confidence intervals ( $\mathrm{CIs}$ ) for each prognostic factor were calculated. When comparative data existed, the odds ratio (OR) was calculated.

Results: The search strategy yielded 2150 relevant citations of which 28 studies were included in the review. The overall rate of infection and chromosomal abnormality was. 1.5 and $5 \%(95 \% \mathrm{CI} 3,7)$, respectively. The risk of neurological abnormality regardless of karyotype or infection screen was $14 \%(95 \% \mathrm{CI} 10,18)$ and this reduced to $12 \%(95 \% \mathrm{CI} 9$, $15)$ when both chromosomes and infection screen were normal. The risk of neurological abnormality was significantly lower in stable compared to progressive ventriculomegaly [OR $0.29(95 \% \mathrm{Cl} 0.15,0.58)]$. No significant differences were detected when symmetrical vs. asymmetrical ventriculomegaly were compared [OR $0.91(95 \% \mathrm{CI} 0.34,2.41)]$.
\end{abstract}

Conclusion: This systematic review provides the physician with some estimates of prognosis in cases of isolated mild to moderate ventriculomegaly.

Keywords: Isolated ventriculomegaly; neurological outcome; prognosis; systematic review; ventriculomegaly.

\section{Introduction}

The width of the fetal cercbral lateral ventricular atrium remains fairly constant at $7.6 \pm 0.6 \mathrm{~mm}$ at $14-38$ weeks' gestation [7]. Ventriculomegaly is defined as dilatation $\geq 10 \mathrm{~mm}$ of the lateral ventricles [ $>4$ standard deviations (SDs) above the mean] [7]. Several classifications of ventriculomegaly exist. Some authors define "borderline" ventriculomegaly as a diameter between 10 and $15 \mathrm{~mm}[4,5,16,22-25,41$, 43], whereas others define mild (or "borderline") ventriculomegaly as between 10 and $12 \mathrm{~mm}$ and moderate ventriculomegaly as between 13 and $15 \mathrm{~mm}[12,13,27]$. In any case, a diagnosis of isolated ventriculomegaly between 10 and $15 \mathrm{~mm}$ (mild to moderate ventriculomegaly) poses a counselling challenge for the clinician and generates anxiety and uncertainty for the prospective parents.

Perhaps one reason why the diagnosis is such a challenge is that the risk of intrauterine infection; aneuploidy and neurological abnormality are poorly quantified. In addition, there is uncertainty as to how these risks alter in cases of asymmetrical ventriculomegaly or when the condition appears to be progressive [16,31].

The purpose of this review is to obtain a more accurate risk estimate to aid the physician in this counselling process. Because of the current different classifications of ventriculomegaly, we have analysed our data of ventriculomegaly of 10.1-15.0 mm, and attempted a sub-analysis of data where ventriculomegaly was between 10.1 and $12.0 \mathrm{~mm}$.

\section{Methods}

This systematic review was based on a protocol developed using widely recommended methods for systematic review of observationa! studies $[18,37]$.

The search strategy involved searching the bibliographic databases MEDLINE and EMBASE between 1980 and 2009 inclusive using OVID search software. The search was performed in April of 2009 and included the search terms "brain ventricular dilatation", "ventriculomegaly" and using a combination of MeSH and text words. Abstracts that met the pre-defined criteria were reviewed by the authors for potential inclusion in the systematic review. The reference lists of included studies were also reviewed for additional relevant studies. No language restriction was applied. Articles in 
languages other than English were translated by a relevant translator. Our study selection criteria were:

\section{Population}

Singleton pregnancy with clear definition of mild to moderate isolated fetal ventriculomegaly $(10.1-15.0 \mathrm{~mm})$.

\section{Outcome}

Assessment of at least one of the following prognostic factors: chromosomal (abnormal karyotype on invasive testing), infectious (positive TORCH screen), haematological or neurological abnormality (method of diagnosis of neurological abnormality was not specified nor duration of foliow-up).

\section{Study design}

Prospective and retrospective studies including case series with follow-up of $\geq 5$ cases. The final inclusion/exclusion decisions were made after evaluation of these criteria by two reviewers (P.D. and S.O.). In cases of data duplication, only the most recent and complete report was included.

One reviewer (P.D.) extracted data from all papers meeting the selection criteria including data on features of methodological quality. This was checked by another reviewer (S.O.). The studies were assessed for quality by the following criteria derived from existing checklists [28].

\section{Data collection}

Prospective collection of data was considered ideal; retrospective collection was considered second best.

\section{Description of population}

A well-defined sample with a clear definition of ventriculomegaly $(10.1-15.0 \mathrm{~mm})$ and clear documentation of gestational age at diagnosis was considered ideal.

\section{Objective outcome}

Clear documentation of at least one of the following prognostic factors: chromosomal abnormality, intrauterine infections, neurological outcome or alloimmune thrombocytopenia were considered ideal.

\section{Prognostic factors considered}

Clear documentation of gestational age at delivery, comparison of asymmetrical vs. symmetrical ventriculomegaly or stable vs. progressive ventriculomegaly in terms of neurological outcome or chromosomal or infective status were considered ideal.

\section{Duration of follow-up}

Follow-up for at least 2 years after birth was considered ideal.

\section{Outcome ascertainment}

Greater than $90 \%$ follow-up of the original study population was considered ideal, $<90 \%$ was considered second best.

Data extraction sought information regarding the overall rate of chromosomal abnormality, infection and neurological abnormality in those fetuses with isolated mild to moderate ventriculomegaly. Information was also sought where there was comparative data between asymmetrical vs. synmetrical and stable vs. progressive ventriculomegaly with regard to neurological outcome, chromosomal abnormality and infective status. A subgroup analysis was also performed for chromosomal abnomality, infection and abnormal neurological outcome for mild ventriculomegaly $(10.1-12 \mathrm{~mm}$ ) where such data were available. Data were extracted to allow computation of odds ratio (OR), stratifying by prognostic factors wherever possible.

The extracted data were tabulated to aliow qualitative inspection for clinical and methodological heterogeneity. For comparison of dichotomous outcomes between two groups, ORs and standard errors (SEs) were calculated for the association in each study. The heterogeneity of estimates was explored graphically using forest plots and formally tested using $\chi^{2}$-tests. The $I^{2}$ statistic was also presented where appropriate to quantify the degree of heterogeneity between the studies [40]. Random-effects models were then used to calculate combined estimates [9] allowing for between study heterogeneity. For proportion outcomes, binomial exact $95 \%$ confidence intervals (Cls) were presented in forest plots as the numerators for some proportions were small. Heterogeneity was formally tested using $X^{2}$-tests [the presented $P$-value was based upon exact Monte Carlo methods, to adjust for any small cell counts, using Statistical Package for Social Services (SPSS)] [35]. A combined proportion was calculated using random effects models on the $\log$ odds scale (where the numerator of a proportion was zero, a correction of a half was added to the numerator and denominator to allow analysis to proceed [38]. Data from individual studies were pooled within subgroups defined by prognosis and outcome [8]. Except where noted, the analysis of ORs was conducted using Review Manager 5 [29] and the analysis of proportions was conducted using STATA v9 [36].

\section{Results}

The electronic search yielded a total of 2150 citations, of which 70 were considered potentially relevant. Examination of the full manuscripts revealed that 42 studies did not meet the selection criteria. Thus, a total of 28 primary studies (1496 pregnancies) were selected for review (Figure 1) [1, $2,4-6,10,12=17,19,20,22-27,30,31,33,34,39,41-43]$. Five studies were prospective $[5,12,30,33,43]$ and the others were retrospective observational studies. Eleven studies $[1,6,12,13,19,22,26,27,33,34,43]$ had information on neurological outcome and 10 of these with the exception of the paper by Alagappan et al. [1] looked at chromosomal abnormality for mild ventriculomegaly $(10.1-12.0 \mathrm{~mm})$. Eight studies $[6,12,19,22,27,33,34,43]$ had information on infection screen in mild ventriculomegaly $(10.1-12.0 \mathrm{~mm})$.

Figure 2 summarises the quality assessment of the studies included in the systematic review. The average gestational age at diagnosis of ventriculomegaly was 25 weeks (range 15-39 weeks). This was reported in $71 \%$ (20/28) of studies. All the 28 studies clearly defined ventriculomegaly.

Four objective outcomes that influenced prognosis were considered. A total of $78 \%(22 / 28)$ of the studies reported chromosomal abnormalities, 53\% (15/28) reported infections, $89 \%(25 / 28)$ reported on neurological abnormality and 
Potentially relevant citations identified by search strategy for MEDLINE, EMBASE and hand search (1980-2009) $n=2150$

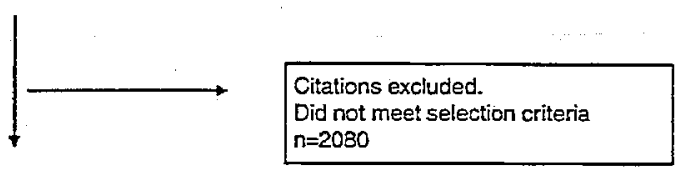

Citations retrieved for detailed evaluation of full manuscript $n=70$

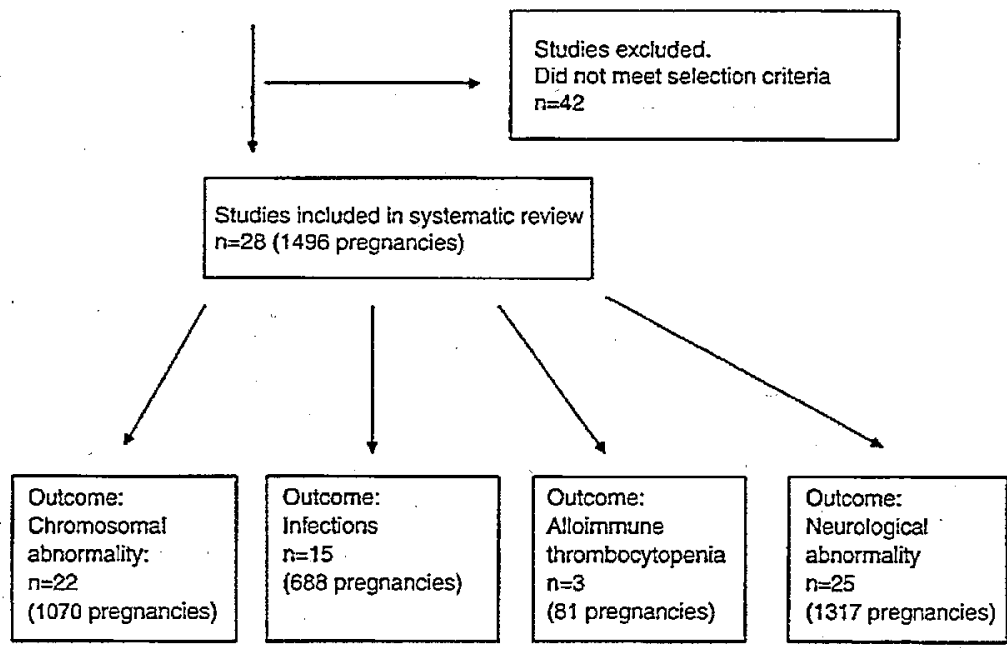

Figure 1 Flow chart of study selection.

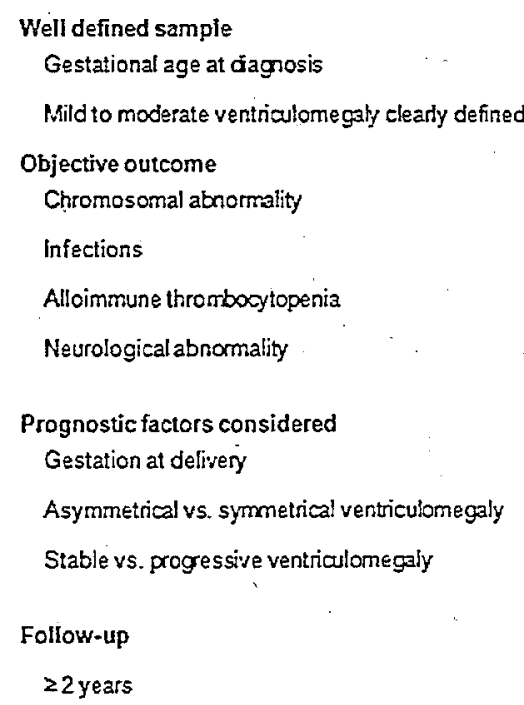

Yes

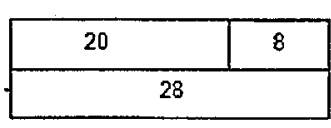

\begin{tabular}{|l|l|l|l|}
\hline \multicolumn{2}{|c|}{22} & 6 \\
\hline & 15 & \multicolumn{2}{|c|}{13} \\
\hline 3 & & 25 & \\
\hline & 25 & & 3 \\
\hline
\end{tabular}

\begin{tabular}{|c|c|c|}
\hline \multicolumn{2}{|c|}{13} & \multicolumn{2}{|c|}{15} \\
\hline 10 & \multicolumn{2}{|c|}{18} \\
\hline 21 & & 7 \\
\hline
\end{tabular}

\begin{tabular}{|l|l|}
\hline 18 & 10 \\
\hline
\end{tabular}

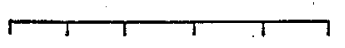

$\begin{array}{llllll}0 & 20 & 43 & 50 & 83 & 100 \%\end{array}$

Nolunclear/not reported

Figure 2 Quality assessment of studies in stystematic review. 
only $10 \%(3 / 28)$ reported on alloimmune thrombocytopenia as an outcome (Table 1). Chromosomal abnormalities were diagnosed by amniocentesis and an infection screen was considered_positive by maternal seroconversion on peripheral venous sample, in all papers reviewed. The methods in assessing neurological abnormality varied. In general, neurological abnormality was classified as mild (delayed motor skill, nystagmus, mild speech impairment) or severe (cerebral palsy, urinary incontinence, blindness, mental retardation). Neurological outcome was assessed either singly or by a combination of clinical assessment, telephone questionnaires and scoring systems (Illingworth's Developmental Screening test, Griffith's Scale, Bayley's Developmental Index, etc.). A total of $64 \%(18 / 28)$ had follow-up data for $\geq 2$ years after birth. The median length of follow-up was 30 months (range 2-72 months).

The paper by Terry et al. [39] describes aneuploidy rates in two different study populations and the data are presented in two separate cohorts (\#-cohort 1; \$-cohort 2).

A total of $75 \%(21 / 28)$ of papers had comparative data between stable vs. progressive ventriculomegaly and $35 \%$
(10/28) provided comparison between symmetrical vs. asymmetrical ventriculomegaly.

\section{Overall rates for mild to moderate ventriculomegaly $(10.1-15.0 \mathrm{~mm})$}

The overall rate of a positive infection screen when isolated ventriculomegaly was identified was $1.5 \%$ (9/586). The overall risk of chromosomal abnormality was $5 \%$ (41/923) $(95 \% \mathrm{CI} 3,7)$. Heterogeneity was evident in these estimates $(\mathrm{P}=0.008)$ (Figure 3 ).

The overall risk of neurological abnormality regardless of karyotype or infection status was $14 \%(155 / 1147)(95 \% \mathrm{Cl}$ 10,18 ; , heterogeneity $\mathrm{P}<0.001$ ) (Figure $4 \mathrm{~A}$ ). The overall risk of neurological abnormality when both the chromosomes and infection screen were normal decreased to $12 \%(48 / 508)$ $(95 \% \mathrm{CI} 9,15)$ and there was less evidence of variation between studies (heterogeneity $P=0.11$ ) (Figure $4 B$ ). The toois used to assess the severity of neurological abnormality varied widely in individual studies from telephone question-

Table 1 Studies selected for systematic review and availability of data for extraction and analysis.

\begin{tabular}{|c|c|c|c|c|c|}
\hline \multirow{2}{*}{ Paper } & \multirow{2}{*}{$\begin{array}{l}\text { Number } \\
\text { of cases }\end{array}$} & \multirow{2}{*}{$\begin{array}{l}\text { Chromosomal } \\
\text { abnormality }\end{array}$} & \multirow[t]{2}{*}{ Infection } & \multicolumn{2}{|l|}{ Data extractable } \\
\hline & & & & $\begin{array}{l}\text { Alloimmune } \\
\text { thrombocytopenia }\end{array}$ & $\begin{array}{l}\text { Neurological } \\
\text { abnormality }\end{array}$ \\
\hline Falip et al., 2007 [12] & 101 & Yes & Yes & No & Yes \\
\hline Gaglioti et al., 2005 [13] & 116 & Yes & Yes & No & Yes \\
\hline Gupta et al., 1994 [17] & 279 & No & No & No & Yes \\
\hline Ouahba et al., 2006 [24] & 167 & Yes & Yes & No & Yes \\
\hline Bloom et al., 1997 [4] & 22 & No & No & No & Yes \\
\hline Patel et a1., 1994 [26] & 44 & Yes & No & No & Yes \\
\hline Vergani et al., 1998 [43] & 48 & Yes & Yes & No & Yes \\
\hline Brown et ai., 1995 [6] & 14 & Yes & Yes & No & Yes \\
\hline Signorelli et al., 2004 [34] & 62 & Yes & Yes & No & Yes \\
\hline Tomlinson et al., 1997 [42] & 46 & Yes & No & No & No \\
\hline Graham et al., 2001 [15] & 34 & Yes & Yes & Yes & Yes \\
\hline Kinzler et al., 2001 [19] & 11 & Yes & Yes & No & Yes \\
\hline Pilu et al., 1999 [27] & 31 & Yes & Yes & No & Yes \\
\hline Leitner et al., 2004 [20] & 57 & No & No & No & Yes \\
\hline Sadan et al., 2007 [31] & 41 & No & No & No & Yes \\
\hline Todros et al., 2003 [41] & 92 & Yes & No & No & Yes \\
\hline Greco et ai., 2001 [16] & 8 & Yes & Yes & No & Yes \\
\hline Mercier et al., 2001 [23] & 26 & Yes & Yes & Yes & Yes \\
\hline Lipitz et al., 1998 [22] & 27 & Yes & Yes & No & Yes \\
\hline Senat et al., 1999 [33] & 13 & Yes & Yes & No & Yes \\
\hline Goldstein et al., 2005 [14] & 26 & Yes & No & No & Yes \\
\hline Breeze et al., $2005[5]$ & 21 & Yes & Yes & Yes & Yes \\
\hline Parilla et al., 2006 [25] & 63 & Yes & No & No & No \\
\hline Alagappan et al., 1994 [1] & 11 & No & No & No & Yes \\
\hline Terry et al., 2000" [39] & 46 & Yes & No & No & No \\
\hline Terry et al., $2000^{5}[39]$ & 24 & Yes & No & No & No \\
\hline Robson et al., 1998 [30] & 50 & Yes & No & No & Yes \\
\hline Durfee et al., 2001 [10] & 7 & No & No & No & Yes \\
\hline Beke et al., 1999 [2] & 9 & No & Yes & No & Yes \\
\hline
\end{tabular}

* Cohort 1.

SCohort 2. 


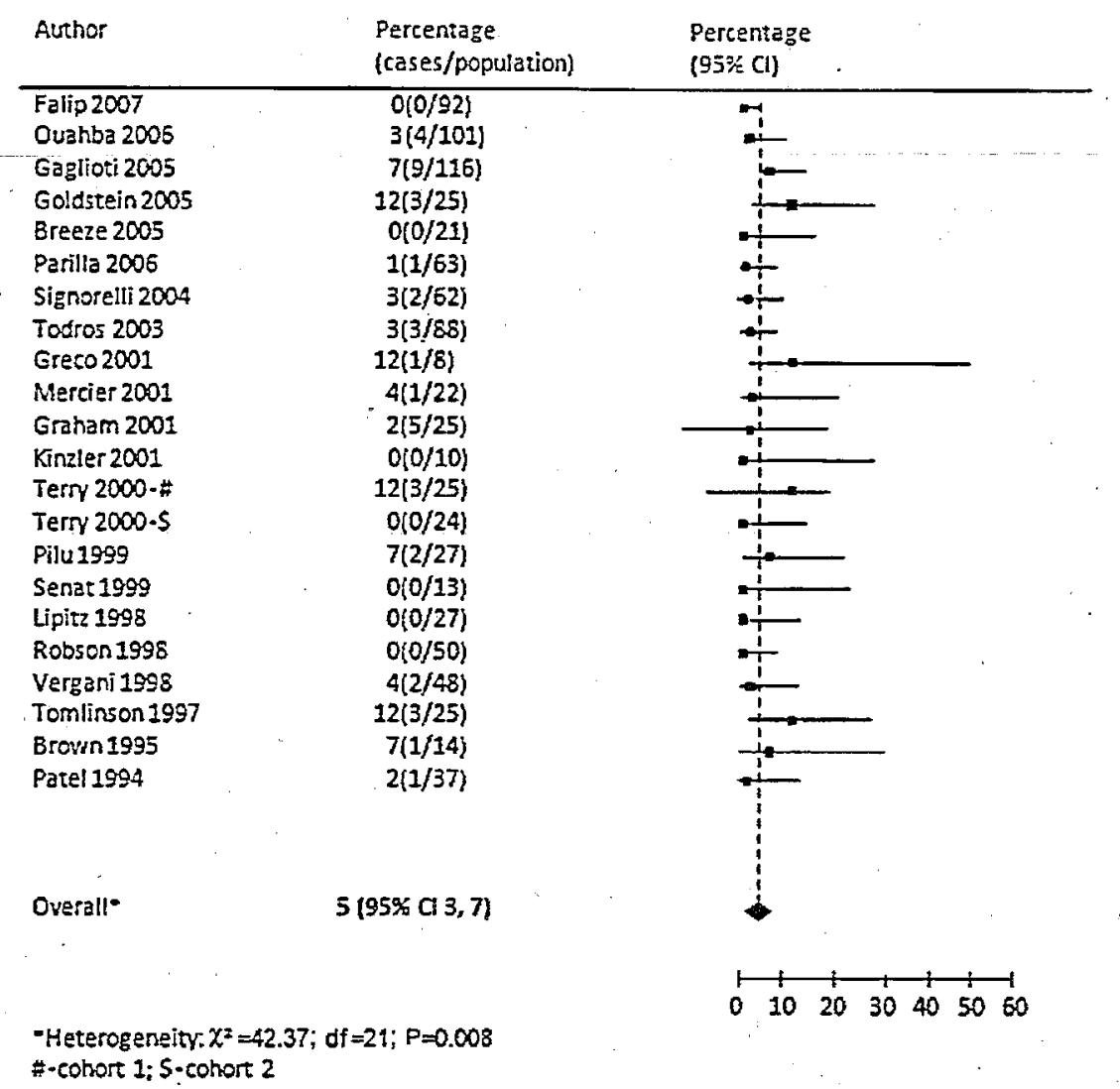

Figure 3 Overall risk of chromosomal abnormality (ventriculomegaly $10.1-15.0 \mathrm{~mm}$ ).

naires to standardised scoring systems making comparisons difficult.

Only three papers reported on alloimmune thrombocytopenia and the overall risk was $4.4 \%(3 / 68)$.

\section{Overall rates for mild ventriculomegaly (10.1-12.0 mm)}

In mild ventriculomegaly $(10.1-12.0 \mathrm{~mm})$ the overall rate of aneuploidy was $3 \%$ (9/310). The overall rate of abnormal neurological outcome was $4 \%(12 / 319)$ (Figure 5A, B). Of the eight papers which provided information on abnormal infection screen for mild ventriculomegaly $(10.1-12.0 \mathrm{~mm})$, the overall rate was $0.4 \%$ (1/235). Because of the small numbers, the CIs and degree of heterogeneity could not be reliably calculated for any of these estimates for ventriculomegaly between 10.1 and $12.0 \mathrm{~mm}$.

\section{Neurological abnormality for mild to moderate ventriculomegaly $(10.1-15.0 \mathrm{~mm})$; stable vs. progressive ventriculomegaly}

Neurological outcome was compared between stable and progressive ventriculomegaly regardless of their karyotype and infection screen. Data were derived from 10 studies involving 451 pregnancies. The overall risk of neurological sequelae in stable ventriculomegaly was significantly lower when compared to progressive ventriculomegaly [OR: 0.29 $(95 \% \mathrm{Cl} 0.15,0.58)]$ and there was little evidence of heterogeneity between the study estimates $\left[I^{2}=0 \% ; P=0.54\right]$ (Figure $6 \mathrm{~A}$ ).

To assess the risk of neurological abnormality between stable and progressive ventriculomegaly when the chromosomes and infection screen was normal, data were derived from eight studies involving 278 pregnancies. The risk of neurological abnormality was significantly lower in stable when compared to progressive ventriculomegaly [OR: 0.32 $(95 \% \mathrm{CI} 0.14,0.73)]$ with little heterogeneity $\left[\mathrm{I}^{2}=0 \%\right.$; $\mathrm{P}=0.55]$ (Figure 6B).

\section{Neurological abnormality for mild to moderate ventriculomegaly $(10.1-15.0 \mathrm{~mm})$; symmetrical vs. asymmetrical ventriculomegaly}

Neurological outcome was compared between symmetrical and asymmetrical ventriculomegaly regardless of karyotype and infection screen. Data were derived from two studies involving 186 pregnancies. The risk of neurological sequelae was not statistically different between symmetrical and asymmetrical ventriculomegaly [OR $0.91(95 \% \mathrm{CI} \quad 0.34$, 2.41)] and this association varied little between studies 
A

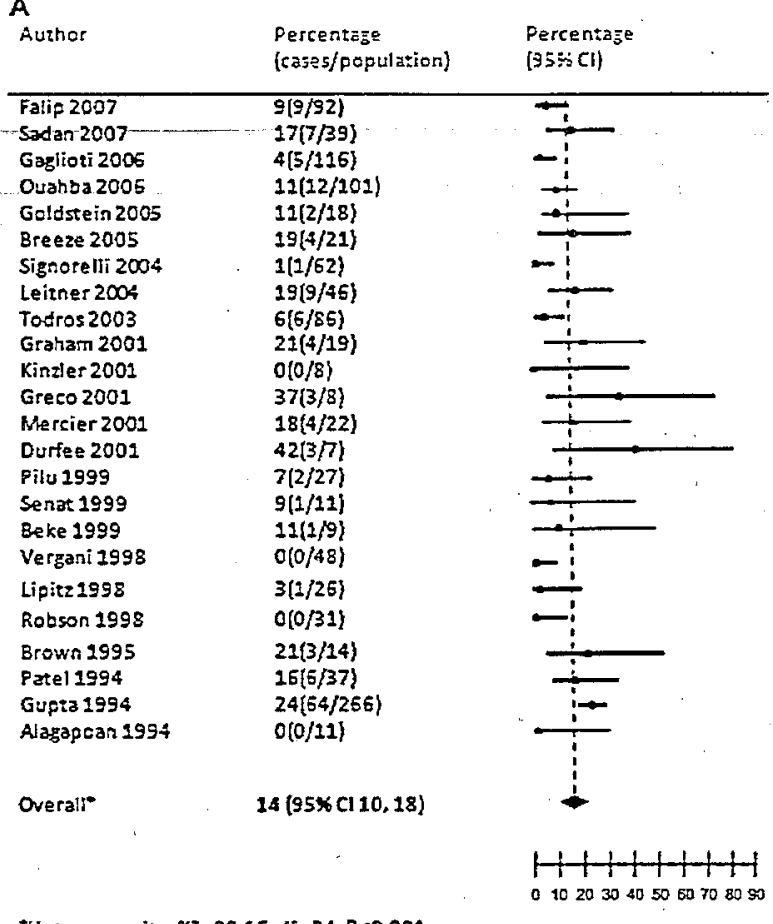

B

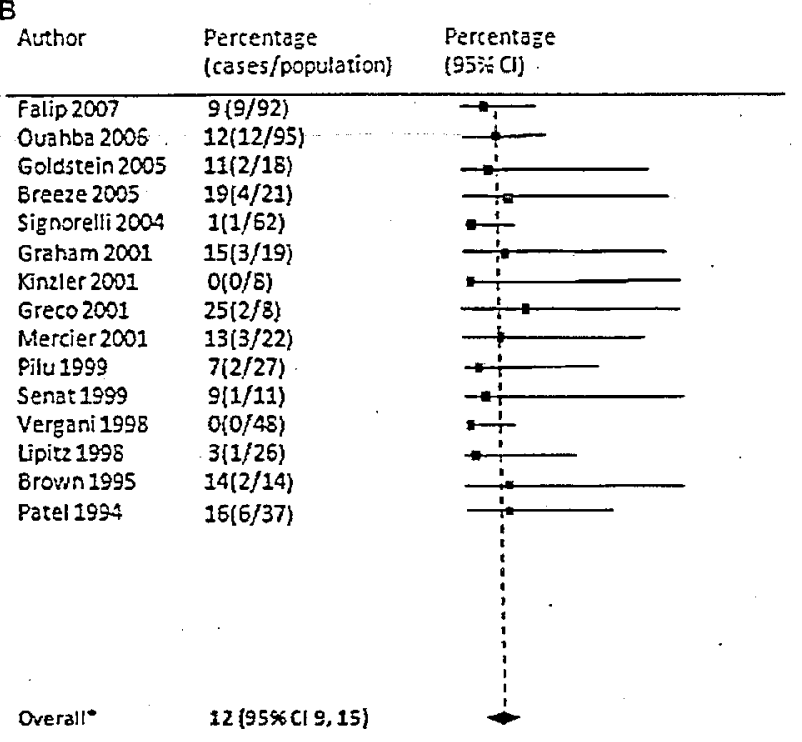

$1+1+1+1+1$

0102030405060708090

theterogeneity: $\chi^{2}=88.15 ; \mathrm{df}=24 ; P<0.001$

Figure 4 (A) Overall risk of neurological abnormality regardless of karyotype and infection status (ventriculomegaly: 10.1-15.0 mm). (B) Overall risk of neurological abnormality with normal chromosomes and normal infection screen (ventriculomegaly: $10.1-15.0 \mathrm{~mm}$ ).

$\left(I^{2}=0 \% ; P=0.96\right)$. With two studies only, this analysis is underpowered. However, these data are presented in Figure 7 along with other studies without comparative data, to illustrate the poor available data.

To assess the risk of neurological abnormality between symmetrical and asymmetrical ventriculomegaly when the chromosomes and infection screen was normal data were derived from two studies involving 180 pregnancies. The risk of neurological sequelae was not statistically different between symmetrical and asymmetrical ventriculomegaly [OR: $1.03(95 \%$ CI $0.39,2.73) ; I^{2}=0 \% ; \mathrm{P}=0.88$ ]. However, with only two studies, this analysis is again underpowered.

\section{Discussion}

This systematic review can provide the physician with some estimates of prognosis. In cases of isolated mild to moderate ventriculomegaly $(10.1-15.0 \mathrm{~mm})$, the risk of infection and aneuploidy is 1.5 and $5 \%$, respectively. The overall risk of neurological abnormality for mild to moderate ventriculomegaly is $14 \%$. If an infection screen and chromosomal status are normal, the overall risk of neurological abnormality falls to $12 \%$. This study also confirms that where the condition is progressive, the risk of neurological sequelae increases.

In cases of isolated mild ventriculomegaly $(10.1-12.0 \mathrm{~mm})$, the risk of infection and aneuploidy is 0.4 and $3 \%$, respec- tively. The overall risk of neurological abnormality is $4 \%$. However, these estimates have to be interpreted with caution because of the paucity of data.

The main strength of this review is that it employed an exhaustive research strategy. In this way, we were able to collate evidence from a reasonable number of studies for a condition that is imprecisely assessed in individual studies. In addition, the quality of these studies was assessed together with stratification of results according to the objective outcomes which influenced prognosis.

There are two important limitations to the evaluation of neurological abnormality in this review. The first is the duration of follow-up after birth. The minimum duration of follow-up was not specified at the commencement of this review. The median length of follow-up was 30 months (range 2-72 months). This is important as subtle learning disabilities may not be apparent until after school age. The second limitation is the methods used in assessing neurological outcome. Again, the tools used varied. In general, neurological outcome was assessed either singly or by a combination of clinical assessment, telephone questionnaires and scoring systems. Although there are a number of standardised screening tools, they vary in their sensitivity and specificity.

We were also unable to sub-analyse our data for mild, moderate and severe neurological abnormality. This information could have been useful to aid parental counselling. The paper by Gaglioti et al. [13] provides a clear classifi- 
A

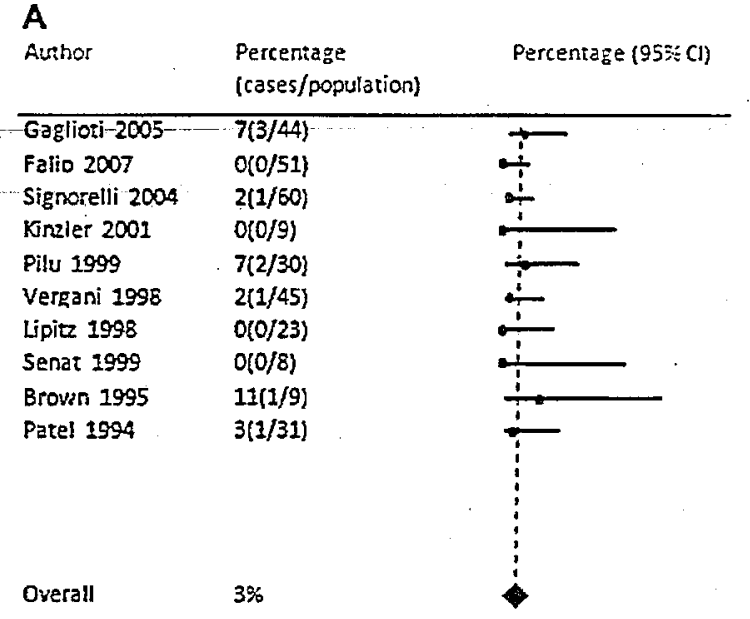

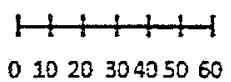

B

\begin{tabular}{|c|c|c|}
\hline Author & $\begin{array}{l}\text { Percentage } \\
\text { (cases/population) }\end{array}$ & Percenteäe $(95 \approx \mathrm{C})$ \\
\hline Gaglioti 2005 & $7(3 / 44)$ & \\
\hline Falip 2007 & $6(3 / 51)$ & \\
\hline Signorelli 2004 & $0(0 / 60)$ & \\
\hline Kinzler 2001 & $0(0 / 9)$ & \\
\hline Pilu 1999 & $7(2 / 30)$ & \\
\hline Vergani 1998 & $0(0 / 45)$ & \\
\hline Alagapozn 1994 & $0(0 / 9)$ & \\
\hline Lipitz 1998 & $0(0 / 23)$ & \\
\hline Senzt 1999 & $0(0 / 8)$ & \\
\hline Brown 1995 & $22(2 / 9)$ & \\
\hline Patel 1994 & $6(2 / 31)$ & \\
\hline Overa!l & $4 \%$ & \\
\hline
\end{tabular}

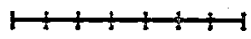

o 10203040505070

Figure 5 (A) Overall risk of chromosomal abnormality in ventriculomegaly between 10.1 and $12.0 \mathrm{~mm}$. (B) Overall risk of neurological abnormality in ventriculomegaly between 10.1 and $12.0 \mathrm{~mm}$.

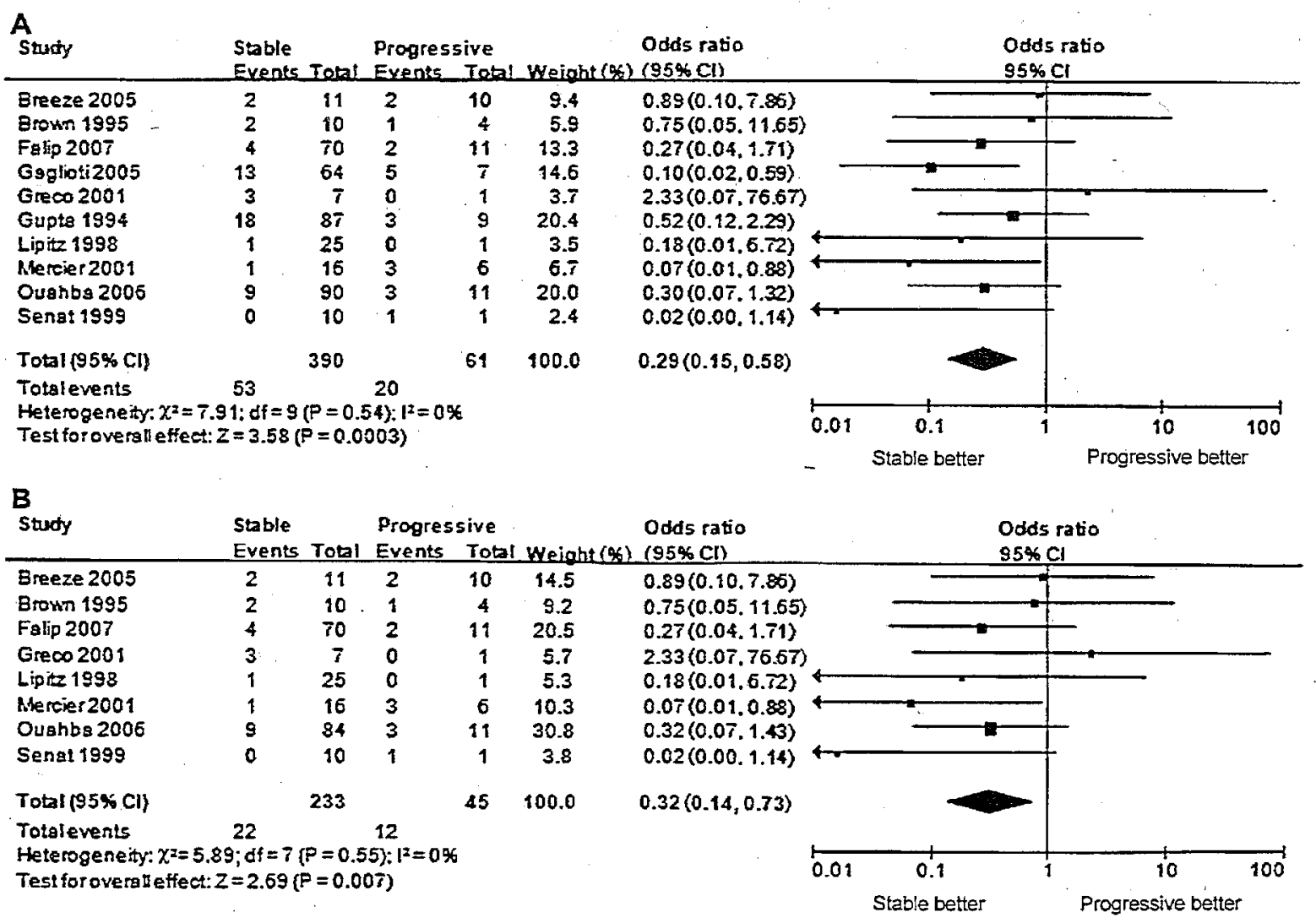

Figure 6 (A) Stable vs. progressive ventriculomegaly. Neurological outcome irrespective of chromosomal or infective status (ventriculomegaly: $10.1-15.0 \mathrm{~mm}$ ).(B) Stable vs. progressive ventriculomegaly. Risk of neurogical abnormality with normal chromosomes and infection screen (ventriculomegaly: $10.1-15.0 \mathrm{~mm}$ ). 


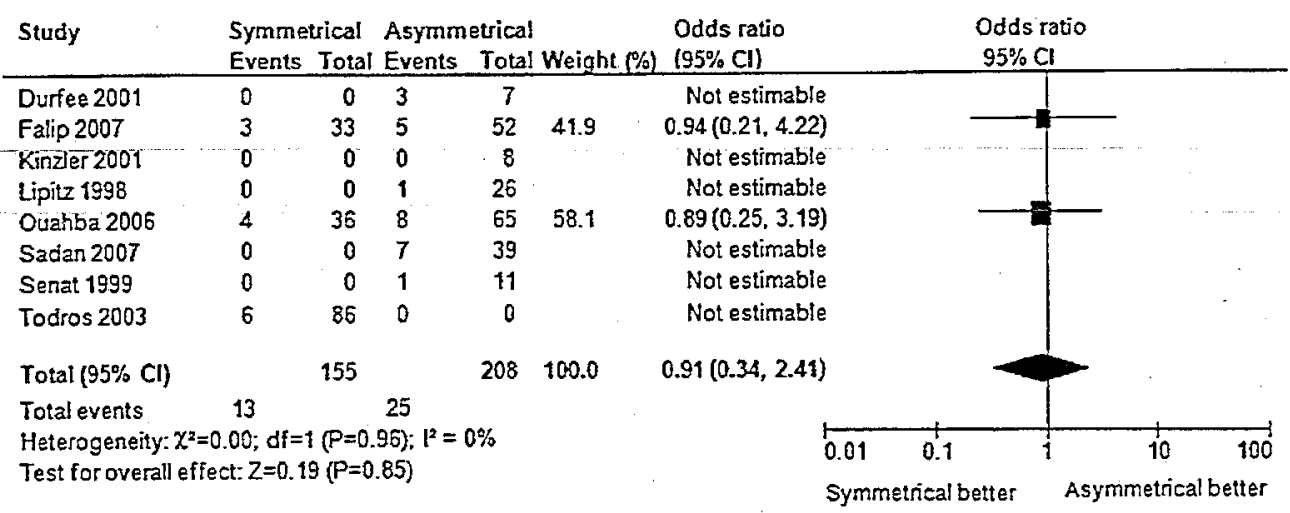

Figure 7 Symmetrical vs. asymmetrical ventriculomegaly. Neurological outcome regardless of chromosomal or infective status (ventriculomegaly: $10.1-15.0 \mathrm{~mm}$ ).

cation of mild to moderate/severe neurological impairment but it was not possible to elucidate the same amount of information from other studies. Moreover, it is impossible to ascertain -if such disabilities are due to the mild ventriculomegaly per se or are due to other factors. The general prevalence of spontaneous mental disability in children is difficult to estimate but is quoted to be around $2-3 \%$ based on population based epidemiological studies $[11,21]$. These figures have to be borne in mind when counselling prospective parents who are faced with the possibility of termination of pregnancy.

It was impossible to control for confounding factors like gestational age at delivery, which was poorly reported. Publication bias may also be an issue, although in this instance, it is unlikely that units with poorer outcomes would be less likely to publish their data. It is difficult to quantify the effect of publication bias on this review.

The number of studies which provided comparative data on symmetrical vs. asymmetrical ventriculomegaly were few and hence we were unable to establish whether this is a significant prognostic factor.

Although this study provides some reliable estimates on prognosis, due to paucity of reporting in individual studies, these data cannot reliably guide clinicians regarding management of pregnancy. The decision to offer termination of pregnancy in a fetus with stable isolated ventriculomegaly is a difficult and complex issue [44]. In addition, the timing of delivery if ventriculomegaly progresses in-ltero remains unexplored. There is urgent need for large scale prospective data.

One source of bias is that most of the studies in this review were from tertiary units. Some studies incorporated in this review included patients from the late 1970 s when the quality of ultrasound machines was poor. Hence, it is possible that mild cases of ventriculomegaly could be underrepresented in this review. Furthermore, the issue of a diagnosis of apparent "isolated ventriculomegaly" is pertinent and is another source of bias. For example, agenesis of the corpus callosum was seldom diagnosed antenatally before 1995 . This systematic review does not address the current trend for MRI of the fetal brain in isolated mild to moderate ventri- culomegaly, where its role remains controversial [3, 32]. Further research might shed light on whether fetal MRI can detect a subgroup of fetuses with apparently isolated ventriculomegaly with underlying occult brain pathology.

\section{Acknowledgement}

We are grateful to Alexandra Mcllroy, Subject Librarian of Queen's University of Belfast Medical Library for her invaluable assistance.

\section{References}

[1] Alagappan R, Browning PD, Laorr A, McGahan JP. Distal lateral ventricular atrium: reevaluation of normal range. Radiology. 1994;193:405-8.

[2] Beke A, Csabay L, Rigo J Jr, Harmath A, Papp Z. Followup studies of newborn-babies with congenital ventriculomegaly. I Perinat Med. 1999;27:495-505.

[3] Benacerraf BR, Shipp TD, Bromley B, Levine D. What does magnetic resonance imaging add to the prenatal sonographic diagnosis of ventriculomegaly? I Ultrasound Med. 2007;26: $1513-22$.

[4] Bloom SL, Bloom DD, DellaNebbia C, Martin LB, Lucas MJ, Twickler DM. The developmental outcome of children with antenatal mild isolated ventriculomegaly. Obstet Gynecol. 1997;90:93-7.

[5] Breeze AC, Dey PK, Lees CC, Hackett GA, Smith GC, Murdoch EM. Obstetric and neonatal outcomes in apparently isolated mild fetal ventriculomegaly. J Perinat Med. 2005;33: 236-40.

[6] Brown IM, Bannister CM, Rimmer S, Russell SA. The outcome of infants diagnosed prenatally as having cerebral ventriculomegaly. I Matern-Fetal Inves. 1995;5:13-9.

[7] Cardoza JD, Goidstein RB, Filly RA. Exclusion of fetal ventriculomegaly with a single measurement: the width of the lateral ventricular atrium. Radiology. 1988;169:711-4.

[8] Dèks J, Altman D, Bradburn M. Statistical methodis for examining heterogeneity and combining results from several studies in meta-analysis. In: Egger $M$, Davey Smith $G$, Altman $D$, editors. Systematic reviews in health care: meta-analysis in context. London: BMI books; 2001. 
[9] DerSimonian R, Laird N. Meta-analysis in clinical trials. Control Clin Trials. 1986;7:177-88.

[10] Durfee SM, Kim FM, Benson CB. Postnatal outcome of fetuses with the prenatal diagnosis of asymmetric hydrocephalus. J Ultrasound Med. 2001:20:263-8.

[11] Emerson E, Hatton C. Mental health of children and adolescents with intellectual disabilities in Britain. $\mathrm{Br} \mathrm{J}$ Psychiatry. 2007;191:493-9.

[12] Falip C, Blane N, Maes E, Zaccaria I, Oury JF, Sebag G, et al. Postnatal clinical and imaging follow-up of infants with prenatal isolated mild ventriculomegaly: a series of 101 cases. Pediatr Radiol. 2007:37:981-9.

[13] Gaglioti P, Danelon D, Bontempo S, Mombro M, Cardaropoli $S$, Todros T. Fetal cerebral ventriculomegaly: outcome in 176 cases. Ultrasound Obstet Gynecol. 2005;25:372-7.

[14] Goldstein I, Copel JA, Makhoul IR. Mild cerebral ventriculomegaly in fetuses: characteristics and outcome. Fetal Diagn Ther. 2005;20:281-4.

[15] Graham E, Duhl A, Ural S, Allen M, Blakemore K, Witter F. The degree of antenatal ventriculomegaly is related to pediatric neurological morbidity. I Matem Fetal Med. 2001;10: 258-63.

[16] Greco P, Vimercati A, De Cosmo L, Laforgia N, Mautone A, Selvaggi L. Mitd ventriculomegaly as a counselling challenge. Fetal Diagn Ther. 2001;16:398-401.

[17] Gupta JK, Bryce FC, Lilford RJ. Management of apparently isolated fetal ventriculomegaly. Obstet Gynecol Surv. 1994; 49:716-21.

[18] Khan $K$, Riet $G$, Glanville J. Undertaking systematic reviews of research on effectiveness. CRD's guidance for carrying out or commissioning reviews. 2nd cd. York: NHS centre for Reviews and Dissemination, University of York; 2000.

[19] Kinzler WL, Smulian JC, McLean DA, Guzman ER, Vintzileos AM. Outcome of prenatally diagnosed mild unilateral cerebral ventriculomegaly. J Uitrasound Med. 2001;20:25762.

[20] Leitner $Y$, Goez H, Gull I, Mesterman R, Weiner E, Jaffa A, et al. Antenatal diagnosis of central nervous system anomalies: can we predict prognosis? J Child Neurol. 2004;19:4358.

[21] Leonard $H$, Wen $X$. The epidemiology of mental retardation: challenges and opportunities in the new millennium. Ment Retard Dev Disabil Res Rev. 2002;8:117-34.

[22] Lipitz S, Yagel S, Malinger G, Meizner I, Zalel Y, Achiron $R$. Outcome of fetuses with isolated borderline unilateral ventriculomegaly diagnosed at mid-gestation. Ultrasound Obstet Gynecol. 1998;12:23-6.

[23] Mercier A, Eurin D, Mercier PY, Verspyck E, Marpeau L, Marret S. Isolated mild fetal cerebral ventriculomegaly: a retrospective anaiysis of 26 cases. Prenat Diagn. 2001;21:58995.

[24] Ouahba J, Luton D, Vuillard E, Garel C, Gressens P, Blanc $\mathrm{N}$, et al. Prenatal isolated mild ventriculomegaly: outcome in 167 cases. BJOG 2006;113:1072-9.

[25] Parilla BV, Endres LK, Dinsmoor MI, Curran L. In utero progression of mild fetal ventriculomegaly. Int J Gynaecol Obstet. 2006;93:106-9.

[26] Patel MD, Filly AL, Hersh DR, Goldstein RB. Isolated mild fetal cerebral ventriculomegaly: clinical course and outcome. Radiology. 1994;192:759-64.
[27] Pilu G, Falco P, Gabrielli S, Perolo A, Sandri F, Bovicelli L. The clinical significance of fetal isolated cerebral borderline ventriculomegaly: report of 31 cases and review of the literature. Ultrasound Obstet Gynecol. 1999:14:320-6.

[28] Rennie D. Improving reports of studies of diagnostic tests: the STARD initiative. J Am Med Assoc. 2003;289:89-90.

[29] Review Manager (RevMan). 5th ed. Copenhagen: The Nordic Cochrane Centre, The Cochrane Collaboration; 2008.

[30] Robson S, McCormack K, Rankin J. Prenatally detected mild/ moderate cerebral ventriculomegaly: associated anomalies and outcome. Norhem Congenital Abnormality Survey Stecring Group. Eur J Pediate Surg. 1998;8(Suppl 1):70-1.

[31] Sadan S, Malinger G, Schweiger A, Lev D, Lerman-Sagie T. Neuropsychological outcome of children with asymmetric ventricles or unilateral mild ventriculomegaly identified in utero. BJOG 2007;114:596-602.

[32] Salomon LJ, Ouahba J, Delezoide AL, Vuillard E, Oury JF, Sebag G, et al. Third-irimester fetal MRI in isolated 10- to 12-mm ventriculomegaly: is it worth it? BJOG 2006;113: 942-7.

[33] Senat MV, Bernard JP, Schwarzler P, Britten J, Ville Y. Prenatal diagnosis and follow-up of 14 cases of unilateral ventriculomegaly. Ultrasound Obstet Gynecol. 1999;14:327-32.

[34] Signorelli M, Tiberti A, Valseriati D, Molin E, Cerri V, Gro] $\mathrm{C}$, et al. Width of the fetal lateral ventricular atrium between 10 and $12 \mathrm{~mm}$ : a simple variation of the norm? Ultrasound Obstet Gynecol. 2004;23:14-8.

[35] SPSS for Windows. Rel. 11.0.1 ed. Chicago: SPSS Inc; 2001.

[36] StataCorp. Stata Statistical Software. Release 9th ed. College Station, TX: StataCorp LP; 2005.

[37] Stroup DF, Berlin JA, Morton SC, Olkin I, Williamson GD, Rennie D, et al. Meta-analysis of observational studies in epidemiology: a proposal for reporting. Meta-analysis of observational studies in epidemiology (MOOSE) group. J Am Med Assoc. 2000;283:2008-12.

[38] Sutton A, Abrams K, Jones D, Sheldon T, Song F. Methods for meta-analysis in medical research. Chichester: Wiley, 2000.

[39] Terry M, Calhoun BC, Walker W, Apodaca C, Martin L, Pierce $B$, et al. Aneuploidy and isolated mild ventriculomegaly. Attributable risk for isolated fetal marker. Fetal Diagn Ther. 2000;15:331-4.

[40] Thompson SG. Why sources of heterogeneity in meta-analysis should be investigated. Br Med J. 1994;309:1351-5.

[41] Todros T, Danelon D, Gaglioti P, Mombro MA. Mild ventriculomegaly in the fetus: perinatal and long-term outcome. Uitrasound Rev Obstet Gynecol. 2003;3:93-6.

[42] Tomlinson MW, Treadwell MC, Bottoms SF. Isolated mild ventriculomegaly: associated karyotypic abnormalities and in utero observations. J Matern Fetal Med. 1997;6:241-4.

[43] Vergani P, Locatelli A, Strobelt N, Cavallone M, Ceruti P, Paterlini G, et al. Clinical outcome of mild fetal ventriculomegaly. Am J Obstet Gynecol. 1998;178:218-22.

[44] Wyldes M, Watkinson M. Isolated mild fetal ventriculomegaly. Arch Dis Child Fetal Neonatal Ed. 2004;89:F9-13.

The authors stated that there are no conflicts of interest regarding the publication of this article.

Received July 2, 2009. Revised December 10, 2009. Accepted December 15, 2009. Previously published online March 18, 2010. 